\title{
PREVALANCE AND ASSOCIATION OF HELICOBATER PYLORI WITH GASTRO-DUODENAL MUCOSAL LESIONS IN PATIENTS WITH DYSPEPSIA
}

\author{
SIDDIQUE AR ${ }^{1}$, HOSSAIN L ${ }^{2}$, RANA MA ${ }^{3}$, BANERJEE PK ${ }^{4}$, RAHMAN A ${ }^{5}$, CHOWDHURY \\ MAU $^{6}$, SINA H $^{7}$, YEASMIN $^{8}$, SIDDIQUE AT ${ }^{9}$
}

\begin{abstract}
Helicobacter Pylori a very common worldwide infection is responsible for number of upper GIT lesions like gastritis, peptic ulcer disease, gastric carcinoma and mucosa associated lymphoid tissue lymphoma. On the other hand, dyspepsia is a wide spectrum of nonspecific upper GIT symptoms for which patients very frequently visit gastroenterology clinics. The objective of the study was to find prevalence of Helicobacter Pylori among the patients with dyspeptic symptoms who had gastro-duodenal mucosal lesions on upper GIT endoscopy and also if there is any association between these two variables.

164 cases of dyspepsia were done index upper GIT endoscopy as per inclusion and exclusion criteria from April 2018 to December 2018 in Seikh Sayera Khatun Medical College Hospital, Gopalganj. Two gastric biopsies (from antrum and body) were taken and immediately placed in a commercial RUT (rapid urease test) kit. Positive test (rapid urease test) was indicated by change in the color of the kit from yellow to pink or red within 24 hours.

Out of 164 patients, 62 (37.8\%) patients had gastro-duodenal mucosal lesions and rest(62.2\%) showed normal upper GIT at endoscopy. Among the 62 patients highest (38) number of the patients endoscopy showed gastritis and least (3) showed gastric ulcer.

Among 62 patients with endoscopic gastro-duodenal mucosal lesions, 36 patients were infected with Helicobacter Pylori. On the contrary 27 patients out of 102 subjects who had normal upper GIT at endoscopy recorded infected with Helicobacter Pylori.

Statistically analysis was done using chi-square test with the help of SPSS software windows version 25. The level of statistical significance was set at 0.05. In our study it was observed that statistically there was significant relation of Helicobacter Pylori with gastro-duodenal mucosal lesions as $P$ value was less than 0.05 .

In this study, we found that Helicobacter Pylori was significantly associated with gastro-duodenal mucosal lesions among the patients with dyspeptic symptoms. So, our suggestion will be to confirm H. pylori infection if anybody has gastro-duodenal mucosal lesions if a subject does upper GIT endoscopy for dyspeptic symptoms.
\end{abstract}

J Dhaka Med Coll. 2019; 28(1) : 100-104

\section{Introduction}

Helicobacter pylori, gram-negative bacteria were first isolated by Warren and Marshall in 1983. It is found in half of the population of the world ${ }^{1}$. Prevalence of $H$. pylori infection appears to be higher in developing countries as compared to industrially developed countries and the prevalence vary between populations and between groups within the same population ${ }^{2,3}$. The prevalence in Asia and Africa varies from $54.7 \%-79.1 \%$, in North and Latin America the prevalence is $37.1 \%$ and $63.4 \%$ and in Europe, the prevalence is typically $47.0 \%{ }^{4}$.

A study conducted in Bangladesh had shown that $60 \%$ children were infected by the age of 3 months and $80 \%$ were infected by the 3 years

1. Dr. Abu Raihan Siddique, Assistant Professor Gastroenterology, Seikh Sayera Khatun Medical College, Gopalganj.

2. Dr. Liakat Hossain, Professor Cardiology and Principal, Seikh Sayera Khatun Medical College, Gopalganj.

3. Dr. Mushtaque Ahmad Rana, Associate Professor Gastroenterology, Bangladesh Medical College.

4. Dr. Probir Kumar Banerjee, Assistant Professor Gastroenterology, Seikh Sayera Khatun Medical college, Gopalganj.

5. Dr. Anisur Rahman, Assistant Professor Gastroenterology, Sher-e-Bangla Medical College, Barisal.

6. Dr.Md. Asraf Uddin Chowdhury, Assistant Professor Cardiology, Seikh Sayera Khatun Medical College, Gopalganj.

7. Dr. Hashmi Sina, Assistant Professor Neurology, Dhaka Medical College.

8. Dr. Sabiha Yeasmin, FCPS Trainee in Gynae-oncology, BSMMU.

9. Dr. Abu Tanvir Siddique, Thesis student-General Surgery, Dhaka Medical College.

Address of Correspondence: Dr Abu Raihan Siddique. Assistant Professor Gastroenterology, Seikh Sayera Khatun Medical College, Gopalganj, Email-raihank55@yahoo.com

Received: 10 February 2019

Revision: 02 March 2019

Accepted: 30 Mach 2019 
of age. ${ }^{5}$ In a study conducted in $1995,92 \%$ of the Bangladeshi population was found to be Helicobacter pylori positive by ELISA. ${ }^{6}$

On the other hand dyspepsia is remarkably common, can be disabling, and can pose a major social and economic burden. ${ }^{7}$

$\mathrm{H}$.pylori is the primary cause of peptic ulcer disease, gastric carcinoma and mucosaassociated lymphoid tissue lymphomas. ${ }^{8}$

In 1994, Helicobacter pylori was classified as a type 1 carcinogen by international agency for Research on cancer . ${ }^{9}$

So, the objective of the current study was to see the prevalence of Helicobacter Pylori among the patients with dyspepsia who had gastroduodenal mucosal lesions on endoscopy and also to establish if there is any relationship of Helicobacter Pylori with gastro-duodenal mucosal lesions who underwent upper GIT endoscopy for dyspeptic symptoms.

In this study, an ulcer in the gastrointestinal tract was defined as a break in the lining of mucosa with appreciable depth at endoscopy and erosions were breaks in the surface epithelium that did not have perceptible depth. The term peptic ulcer disease would be broadly used to include both the ulceration and erosion in the stomach and duodenum.

\section{Methods}

This was cross sectional descriptive study which was done in Department of Gastroenterology in Seikh Sayera Khatun Medical College Hospital from April 2018 to December 2018 among the patients who had undergone upper GIT endoscopy for dyspeptic symptoms .

Dyspepsia includes a series of symptoms: upper abdominal pain, discomfort, nausea, and vomiting, bloating, early satiety. Patients with any 2 out of 6symptoms mentioned above are included in the study. ${ }^{10}$

\section{Inclusion \& exclusion criteria:}

Inclusion criteria:

1. Age between 18 years to 60 years.

2. Endoscopically proven peptic ulcer disease among dyspeptic patients. In this study, an ulcer in the gastrointestinal tract was defined as a break in the lining of mucosa with appreciable depth at endoscopy and erosions were breaks in the surface epithelium that did not have perceptible depth. The term peptic ulcer disease would be broadly used to include both the ulceration and erosion in the stomach and duodenum.

\section{Exclusion criteria:}

1. Use of proton pump inhibitors, H 2 -receptor antagonists, bismuth preparations, and antibiotics in the previous 2 weeks

2. Concomitant anticoagulant, nonsteroidal anti-inflammatory drugs, or ketoconazole use

3. Zollinger - Ellison syndrome

4. Previous surgery of the esophagus and / or the upper gastrointestinal tract (with the exception of appendectomy, polypectomy, and cholecystectomy)

5. Severe or unstable cardiovascular, pulmonary, or endocrine disease

6. Clinically significant renal or hepatic disease or dysfunction; hematological disorders; any other clinically significant medical condition that could increase risk

7. Malignant disease of any kind during the previous 5 years

8. Drug, alcohol, or medication abuse within the past year

9. Severe psychiatric or neurological disorders; and

10. Pregnant women.

Data collection instrument:

History taking and clinical examination

Endoscopy of upper GIT

Rut (Rapid urease test) kits

\section{Methods:}

\section{i. Medical history and physical examination:}

A complete medical history was taken and a thorough physical examination was done.

\section{ii. Endoscopy:}

Upper gastrointestinal endoscopy was done using a standard forward viewing endoscope. In order to prevent contamination from another patient after each procedure endoscope and biopsy forceps were disinfected using glutaraldehyde $2 \%$ (CIDEX) solution. Instruments were immersed in solution and kept for 15 minutes. Side channels were rinsed. 
In this study, an ulcer in the gastrointestinal tract was defined as a break in the lining of mucosa with appreciable depth at endoscopy and erosions were breaks in the surface epithelium that did not have perceptible depth.

\section{iii. H. pylori detection:}

\section{- Rapid urease test}

During endoscopy, two gastric biopsies were collected from each patient from the antrum and the body. With the biopsy sample rapid urease test (CLO test) was done using commercial kits. Patient's whose biopsy sample turned RUT kit red or pink within 24 hour was considered RUT positive. Rapid urease test was done in all patients who went for upper GIT endoscopy irrespective of mucosal lesions to compare the peptic ulcer disease with or without helicobacter pylori infection against subjects with normal endoscopic finding with or without helicobacter pylori infection.

\section{Results:}

Dyspepsia is very common problem. Among the dyspeptic patients a total of 164 patients were underwent index endoscopy and RUT test.

In this study, age range was between 20 to 69 years. It was observed that majority, 25 patients were from 30-39 years of age whereas 2 patients were from 60-69 years of age. The mean age was found $36.95 \pm$ SD 8.43 years. Other age related distributions were shown in the table.

Table I

Age distribution of the patients who had gastro-duodenal mucosal lesions on endoscopy $(n=62)$.

\begin{tabular}{lcc}
\hline Age in years & Frequency(N) & Percent \\
\hline $20-29$ & 10 & 16.1 \\
$30-39$ & 25 & 40.3 \\
$40-49$ & 20 & 33.2 \\
$50-59$ & 5 & 8.0 \\
$60-69$ & 2 & 3.2 \\
\hline Total & 62 & 100.0 \\
\hline
\end{tabular}

Table II shows sex distribution of the study patients. Among the 62 patients who had gastro-duodenal mucosal lesions in endoscopy it was observed that majority, 33 (53.2\%) patients were male and $29(47.8 \%)$ patients were female. The ratio of male to female participants in the study was $1.5: 1$.

\section{Table II}

Distribution of the study patients who had gastro-duodenal mucosal lesion on endoscopy by $\operatorname{sex}(n=62)$

\begin{tabular}{lcc}
\hline Sex of the patients & Frequency $(\mathrm{N})$ & Percent \\
\hline Male & 33 & $54.8 \%$ \\
Female & 29 & $45.2 \%$ \\
\hline Total & 62 & $100.0 \%$ \\
\hline
\end{tabular}

Among the 164 patient who went for upper GIT endoscopy 62 patients had gastro duodenal mucosal lesions whereas 102 patients showed normal upper GIT at endoscopy.

Among the 62 patients highest (38) number of the patients' endoscopy showed gastritis and least (3) showed gastric ulcer. The breakdown of the endoscopic finding of gastro-duodenal lesions is given below.

\section{Table III}

The breakdown of the endoscopic finding of gastro-duodenal lesions

\begin{tabular}{lcc}
\hline Endoscopic Findings & Frequency(N) & Percentage \\
\hline Gastric ulcer & 3 & $4.8 \%$ \\
Duodenal ulcer & 6 & $9.7 \%$ \\
Gastritis & 38 & $61.3 \%$ \\
Gastritis and Duodenitis & 4 & $6.5 \%$ \\
Duodenitis & 11 & $17.7 \%$ \\
\hline Total & 62 & $100 \%$ \\
\hline
\end{tabular}

Among 62 patients who had endoscopic gastroduodenal mucosal lesions, 36 patients had positive Helicobacter Pylori infection by rapid urease test. On the contrary, 27 subjects out of 102 subjects who had normal upper GIT at endoscopy were recorded RUT positive. The data were recorded and analyzed by using SPSS for Windows (Version 25). Data were analyzed by chi-square $(\chi 2)$ test. The level of statistical significance was set at 0.05 , and all tests were two-tailed and data were analyzed to see if there was any association of Helicobacter Pylori with gastro-duodenal mucosal lesions among dyspeptic symptoms who had done upper GIT endoscopy. 
Case Processing Summary

\begin{tabular}{lcccccc}
\hline & Cases & & & & & \\
& Valid & Missing & Total & & & \\
& $\mathrm{N}$ & Percent & $\mathrm{N}$ & Percent & $\mathrm{N}$ & Percent \\
\hline Endoscpy * Rut & 164 & $100.0 \%$ & 0 & $0.0 \%$ & 164 & $100.0 \%$ \\
\hline
\end{tabular}

Endoscpy * Rut Crosstabulation

\begin{tabular}{lllccc}
\hline & & Rut positive & rut negative & Total \\
\hline endoscpy & endoscpoy normal & Count & 27 & 75 & 102 \\
& & Expected Count & 39.2 & 62.8 & 102.0 \\
& & \% within endoscpy & $26.5 \%$ & $73.5 \%$ & $100.0 \%$ \\
& \multirow{4}{*}{ endoscopy lesions } & Count & 36 & 26 & 62 \\
& & Expected Count & 23.8 & 38.2 & 62.0 \\
\multirow{4}{*}{ Total } & Count & 63 & $58.1 \%$ & $41.9 \%$ & $100.0 \%$ \\
& Expected Count & 63.0 & 101 & 164 & \\
& \% within endoscpy & $38.4 \%$ & 101.0 & 164.0 & \\
& & & $61.6 \%$ & $100.0 \%$ & \\
\hline
\end{tabular}

Chi-Square Tests

\begin{tabular}{lccccc}
\hline & Value & df & $\begin{array}{c}\text { Asymptotic } \\
\text { Significance } \\
(2 \text {-sided })(\text { P value })\end{array}$ & $\begin{array}{c}\text { Exact Sig. } \\
(2 \text {-sided })\end{array}$ & $\begin{array}{c}\text { Exact Sig. } \\
\text { (1-sided) }\end{array}$ \\
\hline Pearson Chi-Square & $16.270^{\mathrm{a}}$ & 1 & .000 & & \\
\hline
\end{tabular}

a. 0 cells $(0.0 \%)$ have expected count less than 5 . The minimum expected count is 23.82 . Computed only for a $2 \times 2$ table

In our study statistically shows that there is significant relation with helicobacter pylori with gastro-duodenal mucosal lesions as $\mathrm{P}$ value is less than 0.05 .

\section{Discussion}

Dyspepsia is a very common symptoms. ${ }^{7}$ In the current study we at first try to find out endoscopic lesions among dyspeptic patients. Later on we try to figure out how many patients with gastro-duodenal mucosal lesions are positive for $\mathrm{H}$. pylori thorough RUT test.

As the Helicobacter Pylori is already designated as primary cause for number of upper GIT disorder like peptic ulcer disease, gastric carcinoma and $\mathrm{MALT}^{8}$. So, in our study we try to find the relationship of Helicobacter Pylori with gastro-duodenal mucosal lesions among the patients with dyspeptic symptoms besides finding the prevalence of Helicobacter Pylori among them.

In our total number of patients who had upper endoscopic lesions most of the patient age group fall between 30-39 years of age.

In our study among 164 patients 62 patients had positive endoscopic findings. This means $62.19 \%$ subjects with normal endoscopic findings. This finding is quite similar with previous studies done in Bangladesh. In a study 
done in Saheed Shurawardy Hospital by Ghosh et al. showed $55.6 \%$ of the patients had normal endoscopic study. ${ }^{11}$ Whereas almost similar finding were found by Islam et al. study, where they found $58.14 \%$ subjects had normal gastroduodenal mucosal lesions among dyspeptic patients. ${ }^{12}$

In our study among the 62 patients who had gastro-duodenal lesions on endoscopy 36 patients $(56 \%)$ were positive for Helicobacter Pylori. On the contrary among the 102 patients who had normal upper GIT at endoscopy 27 $(26.47 \%)$ subjects were recorded positive for RUT.

In a study done by Srinivas et al. at Hyderabad in India, they found about $42.85 \%$ of the patients were positive for rapid urease test who had gastro-duodenal lesions in endoscopy. ${ }^{13}$ In another study done by Nahar et al. in Bangladesh they found $72.3 \%$ of the patients with gastritis were positive for Helicobacter Pylori whereas $80.9 \%$ of the patient with duodenitis were positive for H.pylori. ${ }^{14}$ In our study $63.63 \%$ patient with duodenitis were recorded positive for Helicobacter Pylori whereas $52.63 \%$ patients with gastritis were positive for Helicobacter Pylori. So, there is difference in figure if we compare it with the results from Nahar et al. study. One explanation will be patients may not strictly stopped using PPI or over the counter antibiotics which may cause false negative rapid urease test.

In our observation in the present study shows that 36 out of 62 patients who had gastroduodenal mucosal lesions on endoscopy were recorded positive for Helicobacter Pylori. When we did statistical analysis through chi square test using SPSS against result of rut positive of normal upper GIT endoscopy finding, result shows $P$ value less than 0.5 which is statistically significant. So, Helicobacter Pylori has statistically significant relation with gastroduodenal mucosal lesions.

\section{Conclusion}

There appears to be statistically significant association between Helicobacter Pylori infection and gastro-duodenal mucosal lesions on endoscopy. So, our suggestion will be to confirm Heelicobacter Pylori infection if anybody does upper GIT endoscopy for symptoms of dyspepsia and endoscopy shows gastro-duodenal mucosal lesions .

\section{References}

1. Hunt RH, Xiao SD, Megraud F, Bazzoli F, Hamid S et al. World Gastroenterology Organisation Global Guideline: Helicobacter pylori in developing countries. Journal of Clinical Gastroenterology. 2011; 45 (5): 383-388

2. Frenck RW, Jr., Clemens J. Helicobacter in the developing world. Microbes Infect. 2003; 5(8): 705713.

3. Eusebi LH, Zagari RM, Bazzoli F. Epidemiology of Helicobacter pylori infection. Helicobacter. 2014; 19 Suppl 1: 1-5.

4. Hooi JKY, Lai WY, Ng WK, Suen MMY, Underwood FE, Tanyingoh D, Malfertheiner P, Graham DY, Wong VWS, Wu JCY, Chan FKL, Sung JJY, Kaplan GG, Ng SC. Global Prevalence of Helicobacter pylori Infection: Systematic Review and Meta-Analysis. Gastroenterology .2017; 153(2): 420-429.

5. Mahalanhis D, Rahman MM, Sarkar SA, Bardhan PK. Helicobacter pylori infection in young in Bangladesh.Prevalence, socioeconomic and nutritional aspect. Int J Epidemiol. 1996; 25(4):894898.

6. Ahmad MM, Rahman M, Rumi AK, Islam S, Huq F, Chowdhury MF, Jinnah F, Morshed MG, Hassan MS, Khan AK, Hasan M. Prevalence of Helicobacter pylori in asymptomatic population-a pilot serological study in Bangladesh. J Epidemiol. 1997; 7(4): 251-254.

7. Suzuki H, Matsuzaki J, Hibi T. What is thedifference between Helicobacter pylori associated dyspepsia and functional Dyspepsia? J Neurogastroenterolo Motil. 2011; 17(2):124-30.

8. Malfertheiner, Megraud F, Morain C, F Bazzoli, E El-Omar, D Graham, R Hunt,T Rokkas, N Vakil, E J Kuipers.Current concepts in the management of Helicobacter pylori infection: the Maastricht III consensus report. Gut.2007 ;56: $772-81$.

9. Muñoz N. Is Helicobacter pylori a cause of gastric cancer? An appraisal of the seroepidemiological evidence. Cancer Epidemiology Biomarkers and Prevention. 1994 ; 3: 445-51.

10- Scottish guidelines. Available from http:// www.sign.ac.uk/guidelines/ fulltext/68/ section $1 . h$ tml

11. Ghosh DK, Barua UK, Saha SK, Ghosh CK, Rahman M, Alam MR. Endoscopic evaluation of dyspeptic patients. Bangladesh Med J. 2013; 42 (3):82-84.

12. MDU Islam, SHZ Rahman, SM Shamsuzzaman, N Muazzam, A Chowdhury, AR Sarka. Comments on Evaluation of Endoscopic Findings and Detection ofH. pyloriAntibody by Serum IgG ELISA. Faridpur Med Coll J. 2011; 6(1):24-27.

13. Y. Srinivas, P. Kameshwari Prasad, N. Divya Sai. Prevalence and impact of Helicobacter pylori in dyspepsia. Int Surg J. 2016 ; 3(1):305-309.

14 Shamsun Nahar, K. M. Kaderi Kibria, Md. Enayet Hossain, Shafiqul Alam Sarker, Pradip Kumar Bardhan, Kai-sar Ali Talukder, Motiur Rahman. Epidemiology of $\mathrm{H}$. pylori and its Relation with Gastrointestinal Disorders, A Community-based Study in Dhaka, Bangladesh. Journal of GHR. 2018; 7(5): 2709-2716. 